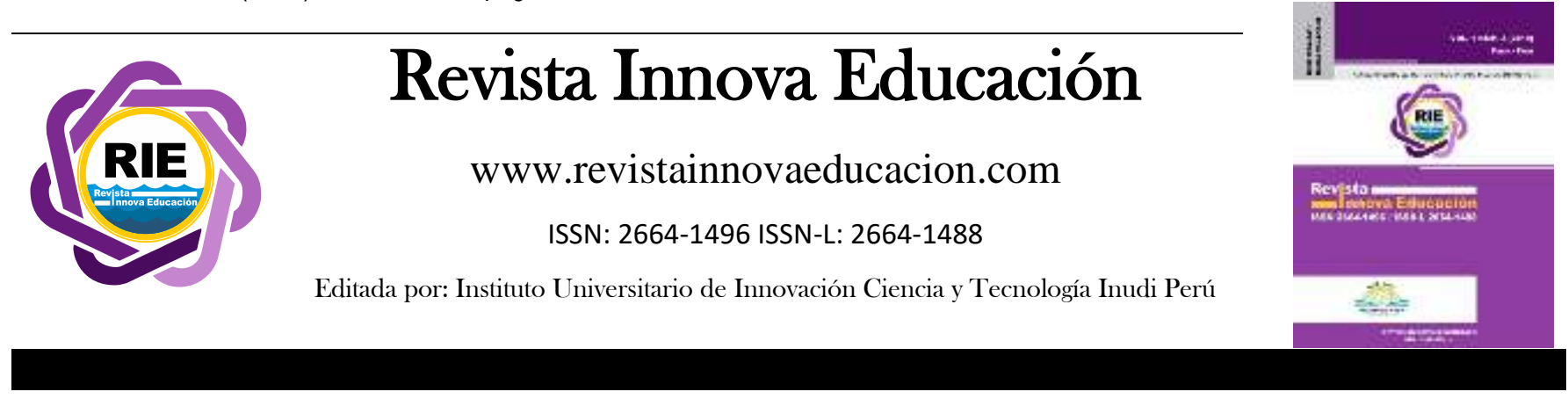

\title{
Aprendizaje universitario: qué es y qué se aprende desde la mirada de los estudiantes. Aportes desde y para la psicopedagogía
}

University learning: what it is and what is learned from the perspective of the students. Contributions from and for psychopedagogy

\author{
Natalia Petric ${ }^{1}$ \\ Universidad Católica Argentina, Buenos Aires- Buenos Aires Argentina \\ Dhttps://orcid.org/0000-0002-5949-993X
}

Wilson Sucari

Universidad Libertaria del Perú, Puno-Puno, Perú

https://orcid.org/0000-0001-5874-0966

DOI: https://doi.org/10.35622/j.rie.2020.04.007

Recibido 09/08/2020/ Aceptado 30/09/2020 Publicado 28/10/2020

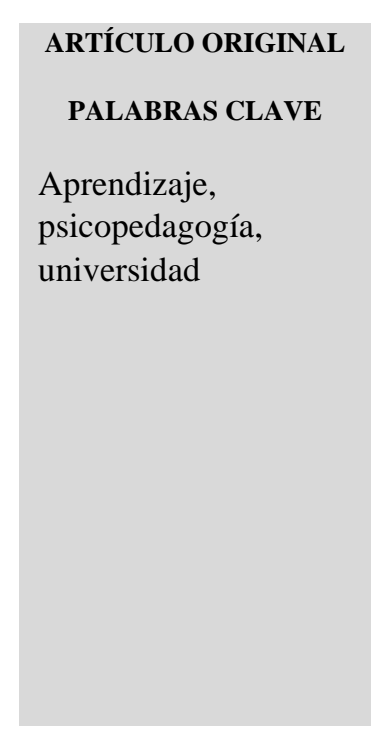

KEYWORDS
RESUMEN. El artículo expone los resultados de una investigación acerca de los significados que los estudiantes universitarios otorgan al aprendizaje que se produce en ese contexto. Se trabajó con un diseño cualitativo con el objetivo de descubrir y profundizar las dimensiones implicadas en dicho aprendizaje, las definiciones acerca del mismo y las estrategias puestas en juego. La muestra se compuso por veinticinco estudiantes del último año de carreras dictadas en la Sede Paraná de la Universidad Católica Argentina (UCA). Se utilizó la entrevista focalizada. La misma incluyó la técnica de elección de objetos que permite construir metáforas, en este caso del aprendizaje universitario. Es así que los hallazgos permiten ampliar la noción de aprendizaje universitario a campos no vinculados directamente al aspecto académico, cognitivo o de rendimiento, sino a cuestiones que especifican las dimensiones curriculares y didácticas, subjetivas, familiares, relacionales y docentes. Además, describen los objetos del aprendizaje (el QUÉ se aprende), dilucidan las definiciones acerca del mismo (QUÉ es) y determinan estrategias para estudiar y para aprobar, modo de aprender y de avanzar en la carrera respectivamente. Las conclusiones remiten a posicionar una ineludible mirada psicopedagógica que articula diferentes marcos teóricos.

ABSTRACT. The article presents the results of an investigation about the meanings that university students give to the learning that occurs in this context. We worked with a qualitative design in order to discover and deepen the dimensions involved in this learning, the definitions about it and the strategies put into play. The sample consisted of twenty-five students of the last year of careers taught at the Paraná Headquarters of

\footnotetext{
${ }^{1}$ Correspondencia: nataliapetric@uca.edu.ar
} 
Learning, psychopedagogy, university the Universidad Católica Argentina (UCA). The focused interview was used. It included the technique of choosing objects that allows the construction of metaphors, in this case of university learning. Thus, the findings allow the notion of university learning to be expanded to fields not directly linked to the academic, cognitive or performance aspects, but to issues that specify the curricular and didactic, subjective, family, relational and teaching dimensions. In addition, they describe the objects of learning (WHAT is learned), elucidate the definitions about it (WHAT it is) and determine strategies for studying and passing, ways of learning and advancing in the career respectively. The conclusions refer to positioning an inescapable psychopedagogical view that articulates different theoretical frameworks.

\section{INTRODUCCIÓN}

El estudio sobre el campo universitario es y ha sido ampliamente abordado desde diferentes perspectivas, disciplinas y enfoques, lo que da cuenta de su complejidad.

Hoy en día una de las principales preocupaciones de las instituciones universitarias, remite a las altas tasas de ingreso (ingreso masivo) y las bajas de tasas de graduación, altos porcentajes de dilación y desgranamiento. Estos indicadores demarcan un contexto por el que transitan miles de jóvenes (y adultos) con expectativas de concretar un proyecto estudiantil que involucra muchas dimensiones vitales.

Desde la última década del siglo XX y sobre todo durante este siglo XXI, la preocupación por el aprendizaje ha pasado a primer plano en Educación Superior. Se propone una nueva cultura educativa, entendida como el enseñar y el aprender para la autonomía (Pozo \& Puy, 2009).

En la actualidad, la Educación Superior plantea como meta central el aprender a aprender (Morchio, 2015). Dicha postura remite al requerimiento de "enseñar a aprender" como una competencia que acompañará el desarrollo profesional posterior. Sin embargo, muchos estudios se posicionan en la perspectiva de estudiar el rendimiento académico como variable central, lo que reduce la experiencia universitaria a ciertas dicotomías reductoras tales como éxito/fracaso o bajo/alto rendimiento (Paivandi, 2019).

Esto se torna relevante en la medida que generalmente, los números que se muestran son un dato que permite visualizar una problemática. Por ejemplo, se expresa que ocho de cada diez estudiantes que egresan del nivel secundario esperan continuar estudios en el nivel superior; no obstante, sólo el $60 \%$ de los ingresantes a la universidad se reinscribe en segundo año; sumado a las bajas tasas de graduación en las carreras universitarias (Cambours \& Gorostiaga, 2016).

Asimismo, la diversidad de experiencias que se producen en las instituciones sociales, en este caso la universidad, habilita la posibilidad de conocer los sentidos que los y las estudiantes otorgan al acto de aprender y las dimensiones que lo posibilitan.

Indagar acerca de la experiencia estudiantil nos posiciona desde una perspectiva teórica y metodológica, que según Carli (2012) permite “...comprender los procesos nodales del devenir institucional, los procesos de identificación intra e intergeneracional y las dinámicas de la producción, trasmisión y apropiación del conocimiento en la universidad” (p. 24). 
Adentrarse en un proceso esencial para la vida estudiantil como es el aprendizaje, remite a la complejidad de su abordaje. Específicamente el aprendizaje universitario ha sido operacionalizado desde diferentes maneras, ya que aprender implica una variabilidad importante de contextos, objetos y sujetos, entre otras dimensiones.

Para el contexto universitario, se han adoptado diversas perspectivas e instrumentos. Estudios clásicos lo han abordado como un proceso que, en etapas, permite el aprendizaje del oficio de estudiante (Coulon, 1995; Perrenoud, 2009). Otro modo, ha sido desde metodologías de corte cuantitativo, a partir de diversos instrumentos estandarizados que evalúan: los enfoques de aprendizajes (De la Fuente et al., 2008; Salim, 2005), los estilos de aprendizaje (Aguilera \& Ortiz, 2009). Y también combinando estas variables (Camarero et al., 2000), y sumando el rendimiento académico (De la Barrera, 2007), o combinando enfoques de aprendizaje y estrategias de aprendizaje (Salim, 2005).

En este sentido, resulta interesante complementar estos abordajes desde la voz de los protagonistas del mismo: los estudiantes universitarios. En consonancia con esto, Tinto (1993) plantea la necesidad de producir investigación cualitativa, "que busque comprender cómo los estudiantes le dan sentido a su experiencia en la universidad" (p. 9), para de esta manera ampliar y complejizar la mirada acerca de este fenómeno constitutivo de las trayectorias estudiantiles.

El incluir la experiencia universitaria, implica atender a las prácticas de los sujetos institucionales y sus reflexiones retrospectivas, y poner en cuestión una mirada generalista para conocer los modos en que los estudiantes transitan la vida universitaria (Carli, 2012).

Dado que las universidades plantean la preocupación por la permanencia, por la calidad de los aprendizajes, por la preparación de los futuros profesionales, por el desarrollo de la autonomía y la competencia para seguir aprendiendo como lo requiere la sociedad del conocimiento, resulta necesario y relevante constituir el aprender en objeto de estudio.

Marton y Säljö en la década del 1970 desde la Universidad de Gotemburgo en Suecia empezaron a gestar los primeros trabajos que desembocarían en la consolidación de la línea de investigación "Students Approach to Learning" (SAL) desde una perspectiva fenomenográfica. Dichos autores entrevistaron a estudiantes universitarios y les preguntaron qué entendían por aprender, y en función de las respuestas describieron seis categorías: incrementar el propio conocimiento; memorizar y reproducir; adquirir, aplicar y utilizar; comprender; interpretar; cambiar como persona (Marton \& Säljö, 1976).

Las tres primeras remiten a concepciones más centradas en la adición de información (de cambio cuantitativo), mientras que las otras hacen referencia al aprendizaje como transformación, tanto en el contenido como en la persona que aprende (aspectos cualitativos).

Este estudio es cimiento de otros, tal como Martínez (2007), quién recupera el planteo de Marton \& Säljö (1976) acerca de la categorización de las concepciones de aprendizaje y reformula en dos polos: uno de corte reproductivo-cuantitativo de suma de informaciones, y el otro de corte constructivo-cualitativo de reflexión, construcción y cambio, con una categoría intermedia de procesamiento guiado. Así, se definen tres categorías: directa reproducción pasiva y copia fiel de 
la información, interpretativa -sujeto activo en el procesamiento de la información con orientación desde fuera y bajo concepciones de dominio general y estable, orientada a lograr una apropiación lo más fiel posible al contenido de aprendizaje-, y constructiva -de procesamiento activo en dominios y contextos específicos con apertura al cambio y el manejo de la incertidumbre.

Otro estudio de corte cualitativo es el de Paivandi (2019) que en el contexto francés elaboró una tipología de perspectivas acerca del aprendizaje que comprende cuatro perfiles: perspectiva comprensiva, minimalista, de rendimiento, y de no implicación.

En Argentina el estudio de Morchio (2015) aborda el aprender a partir de dos grandes dimensiones que condicionarían la conducta del estudiante: las Concepciones y las Experiencias. Entendiendo el aprendizaje universitario entendido como avance en la carrera (aprobar materias).

En la presente investigación nos adentramos a desentrañar cuáles son los aprendizajes (además del académico) que los estudiantes consideran ejes de sus trayectorias universitarias de grado, además de ofrecer una mirada desde la psicopedagogía.

Dicha disciplina, se define como integradora de diversos saberes, y como un espacio complejo, múltiple e interdisciplinario que constituye una praxis donde encontramos personas aprendiendo en diferentes momentos de sus vidas y en los diferentes contextos en los que viven, trabajan, se comunican, se divierten. A su vez, es un saber en expansión por el crecimiento de las investigaciones en el campo y por los cambios operados en el campo social, donde enseñar, aprender, conocer y saber en tanto procesos subjetivos, intersubjetivos, sociales y culturales, ocurren en contextos de cambios macroscópicos de alta complejidad (Müller, 1999). Es así que tanto el aprendizaje como la universidad se constituyen en objetos psicopedagógicos.

\section{MÉTODO}

La investigación tuvo un diseño cualitativo a fin con la producción de conocimiento en base a las experiencias y relatos de los y las protagonistas, específicamente desde la Grounded Theory o Teoría Fundamentada o Teoría Enraizada desde la propuesta de Strauss y Corbin (2002) dada la sistematicidad en los procedimientos que plantea.

Se llevaron a cabo veinticinco entrevistas focalizadas a estudiante que cursaban el último año de carreras universitarias dictadas en Universidad Católica Argentina, Sede Paraná (Licenciatura en Psicopedagogía, Abogacía, Licenciatura en Relaciones Internacionales y Ciencias Económicas).

Dichas entrevistas tuvieron por objetivos sondear las diferentes dimensiones que inciden en una trayectoria universitaria en torno al aprendizaje: curricular, institucional, familiar, subjetiva, relacional y docente, definiciones acerca del aprendizaje universitario, que se aprende en la universidad y estrategias para llevarlo adelante. El diseño de la entrevista incluyó la solicitud a cada participante de la elección de un objeto (fotos, imágenes, palabras, colores, objetos materiales, etc.), que diera cuenta, a modo de metáfora, del aprendizaje en la universidad, acompañado de una explicación acerca del significado otorgado a la elección, a fin de realizar una interpretación fiel a la voz de los participantes, desestimando cualquier interpretación de tipo 
proyectivo.

En este sentido se consideró el aporte de Banks (2010), con relación al análisis de datos visuales en su consideración de las narrativas internas y externas. Las mismas son definidas como la organización intencional de la información presentada. Refiere a la historia que las imágenes cuentan, ampliando la mirada al contexto donde se produce la imagen. El conocimiento del contexto de producción se obtiene activamente mediante indagación empírica en lugar de suponerlo.

El objetivo de esta última técnica fue obtener una aproximación la categoría "aprendizaje" desde una consigna amplia y de significado general, para favorecer la expresión del pensamiento, las creencias, los valores, los sentimientos. Esta técnica, originalmente, se vinculó con la propuesta de Martin-Kniep (2007) quien utiliza objetos (cartas, imágenes, etc.) como forma no convencional de estudiar la práctica docente. Posteriormente fue utilizada y progresivamente adaptada en diversas tesis e investigaciones (Bartolini et al., 2015).

La inclusión de una técnica que tenga por objetivo expresar "de otra manera" el significado del aprendizaje en la universidad, apunta a favorecer el "objetivar", es decir, poner fuera de sí, un proceso que es interno, estableciendo una diferencia con el sujeto, que no anula la relación, sino que la expresa en su complejidad.

El análisis de las entrevistas se realizó en función de las pautas de codificación propuestas por Strauss \& Corbin (2002): primero una codificación abierta, luego axial y luego selectiva a fin de construir categorías centrales. El nivel del análisis es de un ordenamiento conceptual, el que implica la organización de datos en categorías para luego describirlas. Este proceso se realizó con el programa Atlas.ti en su versión 6.2.

El análisis de las metáforas adopto una estrategia inductiva, a partir de la conformación de categorías generales que permitieron organizar la diversidad de materiales: temas, formato, sentimientos. Que luego fueron integrados a los aportes de las categorías analíticas.

El criterio para ambos análisis siguió el razonamiento clásico de categorización que propone en un primer momento minimizar las diferencias y maximizar las similitudes para luego realizar el proceso inverso (Soneira, 2006).

\section{RESULTADOS}

Las categorías construidas permitieron una aproximación descriptiva del aprendizaje universitario.

Se identificaron "Dimensiones" incidentes en el aprendizaje; "Objetos de aprendizaje" (en cuanto al QUÉ se aprende), "Definiciones de aprendizaje" (qué ES el aprendizaje) y las "Estrategias del aprendizaje” (CÓMO aprender).

El siguiente gráfico explicita las categorías y sub categorías. 
Figura 1. Categorías y sub categorías del aprendizaje universitario

\begin{tabular}{|c|c|}
\hline CATEGORÍAS & SUBCATEGORÍAS \\
\hline DIMENSIONES DEL AU & $\begin{array}{l}\text { - Subjetiva } \\
\text { - Familiar } \\
\text { - Relacional (pares) } \\
\text { Docente }\end{array}$ \\
\hline OBJETOS DEL AU (QUÉ) & $\begin{array}{l}\text { - Ampliar experiencias e intereses } \\
\text { - } \quad \text { Oralidad } \\
\text { - } \\
\text { Introyeccimiento y desarrollo de capacidades rol profesional }\end{array}$ \\
\hline ESTRATEGIAS & $\begin{array}{l}\text { - Para estudiar (como modo de aprender) } \\
\text { - Para aprobar (como modo de avanzar en la carrera) }\end{array}$ \\
\hline DEFINICIÓN DE AU & $\begin{array}{l}\text { - Aprendizaje como punto de partida } \\
\text { - } \quad \text { Aprendizaje social } \\
\text { - } \quad \text { Metramientas para aprender } \\
\text { - Aprendizaje } \\
\text { que te pone a prueba }\end{array}$ \\
\hline
\end{tabular}

Fuente: Elaboración propia.

\subsection{Dimensiones del aprendizaje universitario}

Respecto de la dimensión curricular y didáctica, un aspecto significativo fue la valoración del uso de ejemplos y casos prácticos para facilitar la enseñanza de los contenidos:

Me gusta mucho cuando los profesores hacen los Powers Point, por qué es un resumen de resumen y eso te permite hacer tu resumen para poder estudiar (Estudiante de Ciencias Económicas).

La teoría está buena, pero es necesario también que la relacionen con cosas prácticas. Por ejemplo, en derecho te queda más si te relacionan con un caso. A mí por lo menos ver la teoría en la práctica me ayuda muchísimo (Estudiante de Abogacía).

A nosotros lo que nos ayuda mucho son los ejemplos actuales. Con cada materia que vayan haciendo como un paralelismo de lo que está pasando ahora. No solamente la parte política, sino la parte relacional. Por ejemplo, ahora lo que nos estaba explicando la profe sobre la doctrina social de la Iglesia, aplicado a las nuevas tarifas del gas. Entonces ves esa teoría con la práctica, que por ahí es lo que nosotros nos cuesta. En materias que sean como más abstractas o temas muy allá arriba, bajarlos es necesario (Estudiante de Relaciones Internacionales).

En la dimensión institucional, se resaltó principalmente la estructura de tiempos y espacios de cursado, desde una mirada positiva, como negativa también: 
Y a mí me ayudó el tener un espacio. Quizás sí me tendría que haber trasladado a diferentes lugares a estudiar sería difícil. Mi grupo tenía un aula, ya conocíamos los docentes, tener un lugar propio, una sede donde poder estudiar (Estudiante de Licenciatura en Psicopedagogía).

Acá el sistema es estructurado, te persiguen que tenés, que estudiar, hijo del rigor. En la pública tenés esa libertad de hagan como quieran como les guste, las pueden rendir libres y yo no pude (Estudiante de Ciencias Económicas).

La dimensión subjetiva inclinó la balanza al resaltar aspectos personales positivos, como la motivación personal para estudiar, la capacidad de oratoria:

Este año cambié de trabajo. Antes trabajaba en una panadería muchísimas horas. Si no hubiera tenido motivación no hubiera seguido era un sacrificio muy grande (Estudiante de Licenciatura en Psicopedagogía).

Como también el gusto por la carrera vinculado al avance en la misma:

Yo creo que me encanta la carrera, lo que estoy estudiando, las materias. Fue como decir "quiero saber más" y aparte no me cuesta sentarme a estudiar si me gusta, así que es re lindo y además se da, después del primer año, que cuando nos juntamos con el grupo podemos charlar de esto porque ahora sí sabemos. Entonces está bueno (Estudiante de Relaciones Internacionales).

Yo no tuve mucha dificultad al momento de expresar lo que pienso, entonces eso combinado con el estudio, con la teoría y el saber que tal vez no me cuesta tanto encontrar las palabras correctas para decir lo que quiero decir, me ayuda un montón (Estudiante de Abogacía).

La cualidad personal sería la autoexigencia, la constancia y el optimismo. El optimismo frente a todo, nunca salí mal en un parcial, no sé lo que es no aprobar, un final tampoco. Quizás si algún día me pasa estaría re frustrada, baja tolerancia a la frustración, no quiero imaginar ese día (Estudiante de Licenciatura en Psicopedagogía).

La dimensión familiar emerge como posibilitadora, desde el apoyo económico, la ayuda en cuestiones organizativas y el estímulo por estudiar una carrera como posibilidad de ascenso social:

Lo que se habla de tener un futuro. Mis viejos son comerciantes y ellos siempre pensaron y dijeron que iban a hacer todo lo posible para que pudiera terminar una carrera y elegir lo que a mí me gustara (Estudiante de licenciatura en Psicopedagogía).

Que te pueden apoyar económicamente. Tengo compañeros que han tenido que dejar por ese tema. En mi caso que no trabajo, es algo que influye (Estudiante de Relaciones internacionales).

Mi familia... ellos esperaban mucho de mí y si bien cuando dejé, no hubo 
problema, ahora me están ayudando me cuidan a mi hija mientras yo estoy acá, fue por ella también que retomé porque mi mamá se vino a vivir para acá mi hija tiene 4 años (Estudiante de licenciatura en Psicopedagogía).

La dimensión relacional, especialmente el vínculo con pares incide de diversas maneras. La relación con el otro siempre está presente y cada estudiante encuentra los modos de relacionarse en función del estudio:

Las pocas veces que estudie en grupo me servía más el escuchar al otro que yo estudiar (Estudiante de Abogacía).

Particularmente en nuestro año se ha dado que hay muchas chicas que les gusta estudiar de manera individual, no tanto grupal. Yo soy una de las pocas que le gusta en grupo, cuatro personas máximo. Sino se desvirtúa el estudio (Estudiante de licenciatura en Psicopedagogía).

Por último, la dimensión docente se presentó como relevante, denotando características que conjugan la pasión por enseñar y la exigencia:

A lo largo de la carrera me han tocado profesores buenos, más allá de todo lo que uno aprende, te motivan a estudiar más y a conocer más la materia y también el trato que tienen para con los alumnos. Y para mí también es muy importante que el docente tenga en cuenta, que uno está en una etapa de aprendizaje, todo lo que el docente dice es nuevo y todo eso implica aprenderlo también. Tienen esa paciencia y realmente ese espíritu de querer enseñar. Y también he tenido docentes muy malos, que se han confundido con las cátedras, que faltaban, que no iban o no daban bien las clases o no daban el material. La verdad eso obstaculizaba un montón a la hora de aprender, a la hora de estudiar y también de rendir (Estudiante de Abogacía).

$Y$ bueno el tema de las exigencias. Soy una persona que me gusta que me exijan. A todo el mundo no le gusta, pero siento que hace a lo académico. Que te exijan leer un texto, hacer un trabajo práctico y que sea sistemático (Estudiante de Licenciatura en Psicopedagogía).

Creo que los profesores son muy importantes, creo que lo más importante es cómo te transmiten, porque... por ejemplo, hay profesores que te compenetran en las materias y otros que capaz tienen muchos masters y no aprendés nada. Tiene que incentivarte (Estudiante de Relaciones Internacionales).

\subsection{Objetos del aprendizaje universitario: el "Qué" del aprender}

Las subcategorías que permitieron dar cuenta que el aprender en la universidad rebasa el aspecto académico e implica aprendizajes integrales y complejos fueron:

\section{Ampliar experiencias $\mathrm{e}$ intereses:}

Me ayudó a entender mi propio proceso de aprendizaje. También en mi familia, con mi hermana que es adolescente, todo lo que vemos sobre ese tema, diferentes 
aspectos que me ayudan a entender mejor el mundo. También me llevó mucho la reflexión (Estudiante de Licenciatura en Psicopedagogía).

Ha despertado mi curiosidad en otros campos... en el campo de los recursos humanos, en el campo de la comunicación, en el campo de los sistemas organizacionales y en ese sentido, al tener una formación tan variada, te lleva a despertar otros intereses...es como muy integral (Estudiante de Relaciones Internacionales).

La oralidad: un aprendizaje generalmente asociado a la modalidad de exámenes finales, como un aspecto ineludible a ser aprendido:

Con respecto a los exámenes la mayoría son orales con bolillero y me parece que eso está bien porque con relación a la carrera uno tiene que desenvolverse oralmente, porque todo ha ido cambiando. Antes la parte civil era todo escrito en los tribunales y ahora se está desarrollando la oralidad (Estudiante de Abogacía).

Yo soy muy introvertida y por ahí me cuesta hablar en público. Entonces la oratoria, el ponerse enfrente a alguien, me ayudó mucho. En ese sentido lo veo yo, como el cambio más grande (Estudiante de Relaciones internacionales).

Crecimiento y desarrollo de capacidades: esta subcategoría implica variedad de aprendizajes, en cuanto a la misma capacidad de aprender:

Viste cuando dicen que el cerebro es un músculo, bueno, agarras una práctica que cuando vas leyendo va creciendo (Estudiante de Abogacía)

Cómo a modos concretos de estudiar, como modo de aprender:

Me gusta ser organizada ahora pasó todo en computadora y le pongo muchos colores, cuadros. Después imprimo y luego todo en carpetas foliadas. Me gusta que esté todo prolijo y lindo (Estudiante de Licenciatura en Psicopedagogía).

También aspectos subjetivos:

La confianza en mí misma, al ver los logros que iba teniendo, la satisfacción, el creer en uno mismo. Me ayudó muchísimo a saber que si podía con muchas situaciones y eso está bueno a medida que me ponía mal o súper nerviosa o que eran difíciles los finales y luego lograrlo. Al tiempo fui teniendo más confianza en que si podía y con el tiempo aprendí a confiar en mí (Estudiante de Licenciatura en Psicopedagogía).

El aprender a superarse a sí mismos, superar frustraciones:

Una de las cosas que resalto, es darme la posibilidad de fracasar y poder equivocarme. Porque desaprobar en primer año, no estaba en las opciones. Ahora es una opción, desapruebo, se estudia de nuevo y listo. Antes desaprobaba y era una semana que me la pasaba todos los días llorando. Es un crecimiento personal que aprendí que es posible equivocarme. También en lo personal en lo social. 
Siempre fue una persona muy cerrada, me costaba mucho hablar con las personas, entonces los exámenes orales me dieron la posibilidad de abrirme más, a socializar (Estudiante de Ciencias Económicas).

Introyección del rol profesional: esta sub categoría refiere al aprendizaje concreto de aspectos vinculados a la vida profesional próxima futura:

Creo que lo práctico, cuando te dan prácticos, exposiciones. Tuvimos en tercer año es un simulacro de juicio por Jurado, tenés que agarrar un expediente y estudiartelo, para conocer qué pasó en ese caso tratar de defenderlo desde adentro. Consideró que esto es lo más provechoso (Estudiante de Abogacía).

Yo hoy me siento capacitada, calificada mentalmente y académicamente para resolver ciertos problemas. Nosotros siempre trabajamos con un jefe en nuestra profesión, entonces aprendí a cómo llevar una situación como manejarla como definirla, como disponer de un respeto y que valoren tu trabajo, porque veo mis compañeras que creen que se comen el mundo y tenés que aprender cuando sí y cuando no, porque somos recién pichones, no somos contadores todavía (Estudiante de Ciencias Económicas).

\subsection{Definición de aprendizaje universitario}

Las definiciones aportadas por los entrevistados, se categorizaron en función de la textualidad aportada y de la elección de los "objetos" que metaforizaron el aprendizaje universitario, encontrándose muchos puntos en común lo que permitió validar las construcciones categóricas.

La primera categoría permite entender este aprendizaje como un punto de partida para posteriores aprendizajes ya vinculados al mundo laboral, además de entender la provisoriedad de los mismos y la necesidad de seguir ampliando y actualizando conocimientos:

Vas aprendiendo algo y te vas dando cuenta que te falta mucho más para aprender. Sabés un montón de perspectivas para mirar situaciones que te ayudan un montón, pero también necesitás perfeccionarte. Por ejemplo, en cosas económicas, sabés qué significan ciertos conceptos y podés mirar de ese modo, pero también necesitás especificarte o centrarte en un tema. Me falta un montonazo todavía (Estudiante de Relaciones Internacionales).

Creo que a nivel sociedad estamos todos cambiando y si hay un contenido que quedó atrasado, es porque también la sociedad va cambiando principalmente nosotros que trabajamos con discapacidad y con dificultades que van cambiando... (Estudiante de licenciatura en Psicopedagogía).

Las metáforas también aportaron a esta categoría. En el caso que se muestra, el aprendizaje universitario como posibilitador de un cambio y construcción social. 
Figura 2. Metáfora Aprendizaje como punto de partida (Estudiante de Relaciones Internacionales)
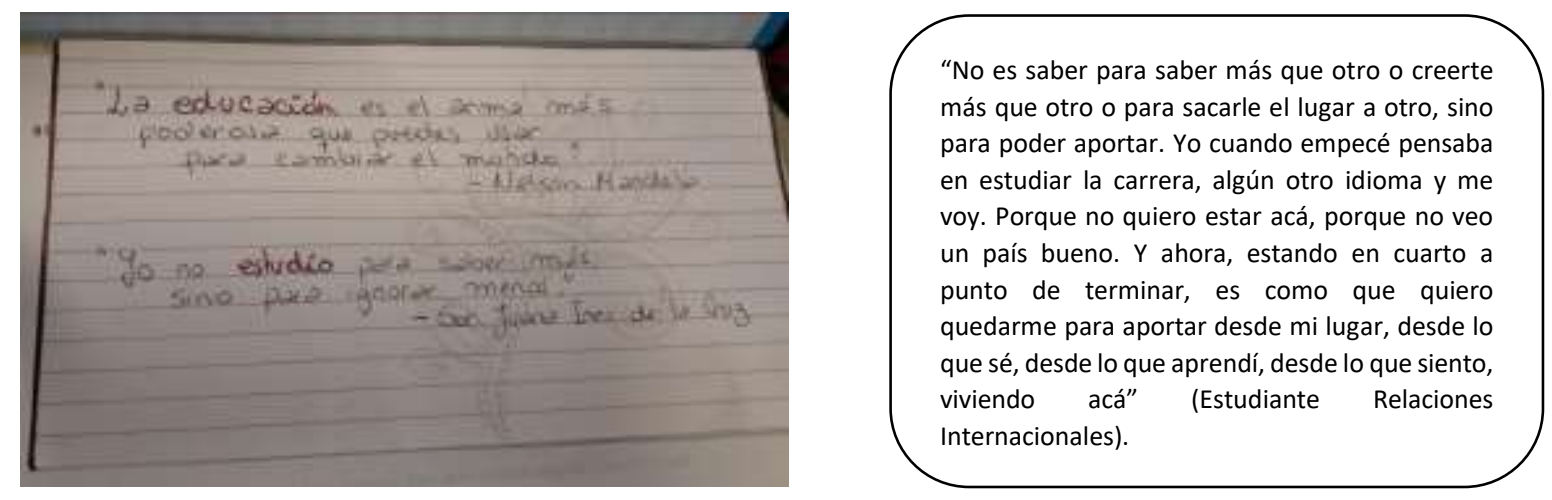

Fuente: Fotografía del material aportado por estudiante de Relaciones Internacionales

También la metáfora elegida por una estudiante de Lic. en Psicopedagogía, propone un continuum entre su bagaje personal, lo actual (universitario) y lo que vendrá a partir de lo logrado:

Figura 3. Metáfora Aprendizaje como punto de partida (Estudiante de Licenciatura en Psicopedagogía)

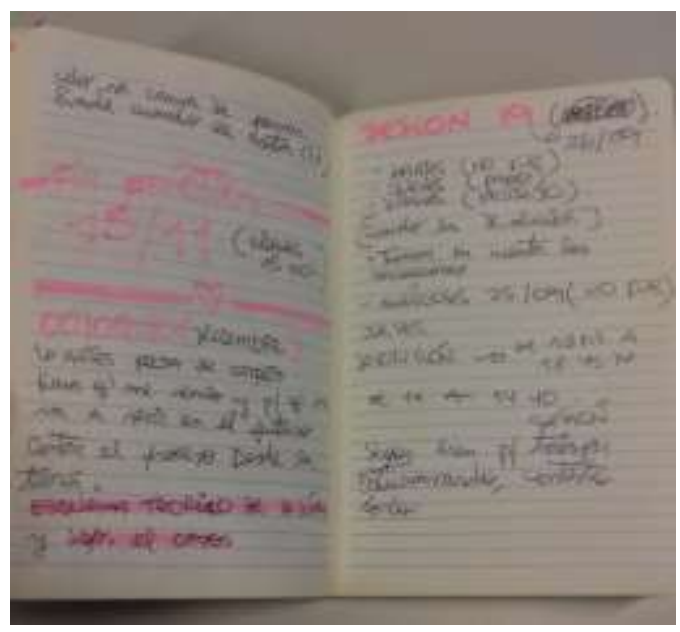

Traje mi agenda. Es muy particular porque tengo algunas cosas anotadas, tengo páginas en blanco... es como una agenda común, tipo libro de viaje. Tengo cosas anotadas que vendrían a ser mis experiencias previas de la otra carrera, cosas que ya están, otras hojas nuevas de otros colores que en mayor o menor medida de universidad y hojas en blanco que son las que tengo que seguir escribiendo después de que salga de acá porque sé que la facultad es un puntapié para yo poder seguir el día de mañana profundizando en la profesión (Estudiante de Licienciatura en Psicopedagogía).

Fuente: Fotografía del material aportado por estudiante de Licenciatura en Psicopedagogía

Otra categoría remite al Aprendizaje social (con otros y de los otros), en el siguiente caso probablemente incidido por la carrera de base (Lic. en Psicopedagogía):

Lo podría definir como un aprendizaje conjunto que se realiza en un espacio común que es la universidad, que te da la posibilidad de ir modificando ciertos esquemas propios del aprender y que te brinda un espacio de interacción con el otro, que es lo más importante de la universidad, la interacción con otros. No te habló sobre del vínculo de amistad que uno puede hacer, sino del vínculo de aprendizaje que se da respecto de los diferentes puntos de vista, los debates que se pueden armar en un aula (Estudiante de licenciatura en Psicopedagogía). 
La metáfora que define el aprendizaje como social, respecto los pares y los docentes y además refiere al oficio de estudiante, fue la siguiente:

Figura 4. Metáfora Aprendizaje social (Estudiante de Abogacía)

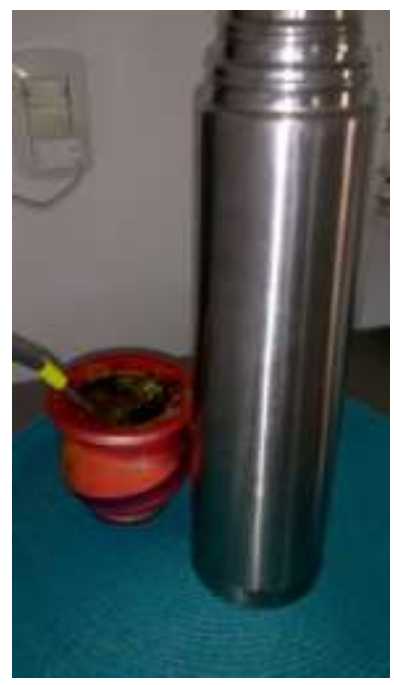

"El mate, porque te acerca, tanto a los compañeros para intercambiar ideas, resúmenes, como también para acercarte al profesor. Porque yo siempre iba con el mate y les convidaba todos, y te decían el pibe del mate a ver si contesta esta pregunta. Entonces por ahí zafaba si no la sabía, al menos le daba un mate." (Estudiante de Abogacía)

Fuente: Fotografía del material aportado por estudiante de Abogacía

La siguiente sub categoría refiere al aprendizaje como, herramientas para aprender a estudiar (de manera general y disciplinar)

Para mí fue empezar a aprender a estudiar, como todos los pasos que uno tiene para decir "yo acá aprendí a estudiar" (Estudiante de Abogacía).

También se expresó metafóricamente a partir de la los objetos elegidos por una estudiante de Ciencias Económicas:

Figura 5. Metáfora Herramientas para aprender (Estudiante de Ciencias Económicas)

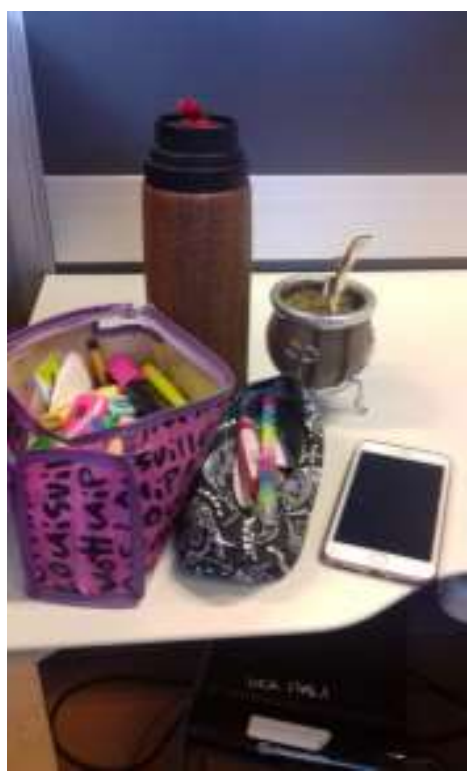

Mis colores: porque todos te dicen que es un bodrio estudiar, entonces encontrarle el lado divertido. ¿¡il que me conoce me dice "estás estudiando para contador!?", porque soy una maestra jardinera!

El celu que es mi calendario, mis contactos, mi desahogo, donde me contactó con las chicas de la facu, me desquito, me entretengo, abro el mail. El celu es todo, también tengo los Power Point en el Google Drive. Entró lo veo lo mando. (Estudiante de Ciencias Económicas). 
Fuente: Fotografía del material aportado por estudiante de Ciencias Económicas

La siguiente metáfora remite a una herramienta aprendida en la facultad, pero central para el futuro profesional:

\section{Figura 6. Metáfora Herramientas para aprender (Estudiante de Ciencias Económicas)}

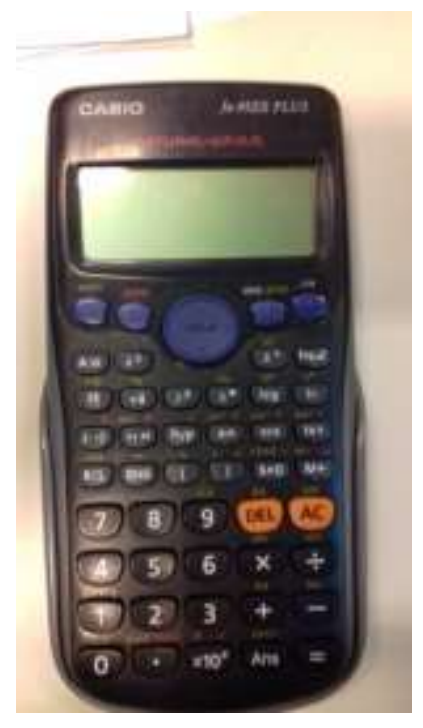

Es como mi tercer mano. Es muy raro que en alguna materia no la usemos, excepto los Derechos, pero el resto de las materias en todas la usamos. Todo está acá, la solución está acá en la calculadora. Hay materias que si no tenés una calculadora, no las podés hacer.

Aprendí a usarla acá en la en la facultad, porque la secundaria usaba la común, la básica...

(Estudiante de Ciencias Económicas)

Fuente: Fotografía del material aportado por estudiante de Ciencias Económicas

La siguiente categoría refiere a un meta aprendizaje, una reflexión acerca del proceso de aprender. En este sentido, definiendo como un proceso costoso, pero de mejoras:

Un camino difícil, que se fue haciendo de a poco, que primero pasó una huella y después se fue poniendo asfalto, luminarias de a poco. (Estudiante de Abogacía).

También referidas a la actitud a tomar frente a esa experiencia, específicamente referida al modo de organizarse frente al estudio:

Es un proceso. Lo comparaba con una torta: o te la vas a comer apurado o la podés comer despacito, en cada porción. Y las materias exactamente lo mismo, si empezás a leerla la primera semana de cursado, vas a llegar, pero tranquilo, vas a rendir, porque ya vas aprendiendo y si se te van presentando dudas las vas resolviendo en el camino o en las clases y el final es casi un coloquio tranqui (Estudiante de Abogacía).

También metaforizando el proceso mismo: 
Figura 7. Metáfora Meta aprendizaje: proceso (Estudiante de Relaciones Internacionales)

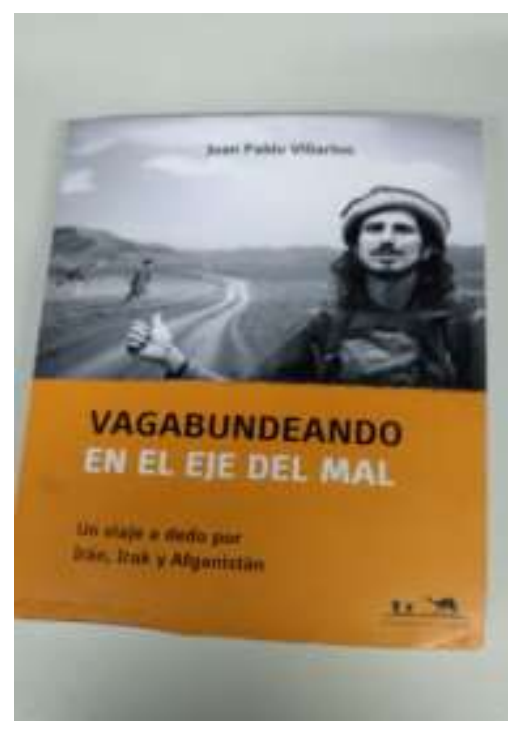

“Podría ser cualquier libro. Pienso que la tapa y el nombre te va a decir algo, la contratapa también. Ese sería nuestro inicio y nuestro final, pero el medio siempre te va a enseñar mucho más, va a tener ilustraciones, va a tener cosas buenas, va a tener cosas malas, pero en el final la conclusión siempre está buena...entonces me parece que la metáfora del libro va muy de la mano de la vida universitaria" (Estudiante de Relaciones Internacionales).

Fuente: Fotografía del material aportado por estudiante de Relaciones Internacionales

En referencia al carácter procesual del aprendizaje y en vinculación al objeto disciplinar, la siguiente metáfora resalta el respeto a los tiempos que implica el proceso de aprender:

Figura 8. Metáfora Meta aprendizaje: proceso (Estudiante Lic. Psicopedagogía)

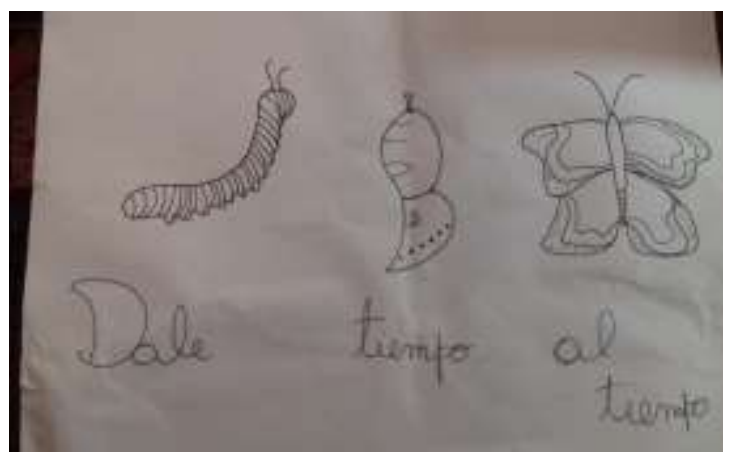

"Creo que todas las personas tenemos diferentes momentos, diferentes tiempos en este proceso de aprender. Y quizás a veces hay compañeros que se traban y compañeras que no cumplen los cuatro años y requieren un tiempo más por circunstancias de la vida personal. Es entonces respetar el tiempo de cada uno y que siempre (pienso positivamente) vamos a llegar al final objetivo. Fue siempre mi lema; capaz que te vas a recibir antes o después, que vas a terminar la secundaria antes o después, todos tenemos un tiempo y vamos a llegar al objetivo o al fin que nos planteamos" (Estudiante de Lic. en Psicopedagogía).

Fuente: Fotografía del material aportado por estudiante de Lic. En Psicopedagogía

Por último, la categoría denominada “aprendizaje que te pone a prueba”, es una categoría nativa que expresa el aspecto integral del sujeto al encarar la tarea de aprender:

Además del contenido, creo que te conoces vos, en la situación de estrés, en la situación del éxito, de compartir (...) Es difícil, es un aprendizaje que te pone a prueba, donde uno se tiene que ir adaptando y cambiando y modificando constantemente (Estudiante de Licenciatura en Psicopedagogía)

La siguiente definición manifiesta la implicación personal en el aprender:

Yo creo que no es sólo académico, sino de la vida general. Uno aprende mucho, ¿viste cuando dicen que las parejas son un espejo de lo que uno es?, bueno la 
universidad es así porque depende de tu personalidad cómo vas a afrontar las cosas (Estudiante de Ciencias Económicas).

\subsection{Estrategias del aprendizaje universitario}

La última categoría refiere a las estrategias, entendidas como acciones dirigidas a un fin, necesarias para la vida universitaria. Aquí se constituyeron dos sub categorías: estrategias para estudiar (como modo de aprender) y estrategias para aprobar (como modo de avanzar en la carrera).

Textualidades de la primer sub categoría expresaron lo siguiente:

Cuando voy a rendir un final trato de enfocarme en lo que sé. De enfocarme y de tratar de convencer a la otra persona que realmente yo sé (Estudiante de Abogacía).

Y respecto de las estrategias para estudiar:

Las exposiciones orales y los exámenes orales me ayudaron mucho a cambiar a forma de estudiar, realizar cuadros, grabarme, escucharme, ver cómo habló, si estoy utilizando un vocabulario técnico. Me costó porque venía con el mecanismo de hacer un resumen y estudiar textual, entonces me ayudó mucho el poder estudiar con otros, aunque también me costó por ser tímida (Estudiante de licenciatura en Psicopedagogía).

\section{DISCUSIÓN Y CONCLUSIONES}

La investigación permitió reconocer que el aprendizaje generado en el ámbito universitario excede ampliamente los componentes cognitivos o académicos, e impregna la subjetividad de los/las estudiantes, los "pone a prueba".

Como síntesis de los hallazgos se pueden enunciar las siguientes proposiciones:

Las dimensiones que inciden en el aprendizaje universitario, adquieren cualidades específicas. Los curricular y didáctico fue tematizado a partir de la importancia del uso de ejemplos, casos y aplicaciones prácticas de contenidos teóricos.

Dentro de la dimensión institucional se resaltó la estructura y organización de tiempos y espacios para el cursado, propio de una institución privada.

La dimensión subjetiva indicó características positivas de la personalidad como la motivación, la responsabilidad, capacidad verbal y el optimismo.

La dimensión familiar refirió al apoyo económico y emocional. La dimensión relacional, el vínculo con pares adquirió diferentes matices, de mayor intimidad o más focalizados en el estudio. La dimensión docente relató una enseñanza que combina el gusto y placer por enseñar y 
la exigencia.

Respecto a los objetos del aprendizaje, el qué se aprende, se encontró que la universidad permite ampliar experiencias e intereses, adquirir capacidad de oratoria a partir de la exposición oral en finales, desarrollar capacidades, madurar e introyectar el rol profesional de manera vinculada a la posibilidad de realizar prácticas pre profesionales.

Las definiciones de aprendizaje universitario, permiten entenderlo como un punto de partida de nuevos aprendizajes y experiencias, también de la sociabilidad con pares y docentes. Además, la apropiación de herramientas para aprender a estudiar en general y específicamente cuestiones propias de la disciplina; como también meta cognitivamente, reflexionar sobre el proceso que demanda el mismo aprendizaje. Y definirlo como un aprendizaje que pone a prueba, desafía de manera integral a los y las estudiantes.

Por último, las estrategias para aprender se especifican en dos modalidades: para estudiar como modo de aprender y para aprobar, como modo de avanzar en la carrera.

Estos hallazgos pueden ser leídos de manera consonante con el modelo psicopedagógico, planteado por Cabrera et al. (2006), si bien en el análisis de la deserción estudiantil. El mismo explica la actuación de los estudiantes en el ámbito universitario a partir de la confluencia del modelo de adaptación, más el modelo estructural y cuestiones psicoeducativas. Del modelo estructural, los aportes de Tinto (1989) en su Teoría de la Persistencia aportan los factores sociales y relacionales como una función central del ajuste (integración) entre el estudiante y la institución. Los aspectos positivos enunciados en la dimensión subjetiva, validan los aportes de la psicología positiva acerca del optimismo aprendido, la autoeficacia y la autoestima (Seligman, 1990).

Además, los hallazgos son consonantes con las perspectivas de enseñanza orientadas al desarrollo de competencias: genéricas (aprendizaje para la vida en los ámbitos personal, académico y profesional), disciplinares (campos o áreas de conocimiento especializado) y profesionales (formación en el rol profesional correspondiente) (Heredia, 2018).

Otro elemento que favorece la discusión es el planteo de Pozo \& Puy (2009), acerca del objetivo de la enseñanza universitaria -en un contexto europeo de formación- como instancia formadora de aprendices y futuros profesionales capaces de usar el conocimiento en forma autónoma y estratégica, y de la necesidad de formar en competencias (leer, escribir, producir, e interpretar gráficos, buscar y seleccionar información, fijarse metas y cooperar, resulta de relevancia con relación a los aprendizajes de los contenidos disciplinares). Este planteo focaliza en las estrategias tanto para estudiar como para aprobar, pero descuidan la variedad de experiencias que atraviesan a los sujetos universitarios y el carácter subjetivante de la educación, en cuanto formadora no solo en aspectos curriculares y disciplinares, sino en cuestiones ligadas a la identidad, al ser.

En este sentido, para comprender lo que las instituciones educativas "fabrican", no basta con estudiar los programas, el rendimiento, los roles y los métodos de trabajo, sino que es necesario captar la manera con que los alumnos transitan su experiencia, es decir, fabrican relaciones, estrategias, significaciones a través de las cuales se constituyen en ellos mismos (Walker, 2012). 
Estas ideas están en sintonía con lo expresado por Lucarelli (2009), quién señala que la universidad, como objeto de estudio, en su complejidad admite un abordaje polifacético y desde múltiples enfoques disciplinarios, lo que permite aventurar el pensamiento en dirección a lo que podría ser una psicopedagogía dedicada explícitamente al ámbito universitario, una psicopedagogía universitaria.

La psicopedagogía, como saber en constante desarrollo, avanza en la construcción de marcos teóricos asentados en investigaciones empíricas, que no descuidan el carácter interdisciplinar de sus orígenes. La naturaleza misma del objeto de la intervención psicopedagógica, su complejidad reclama un abordaje e inteligibilidad desde múltiples perspectivas.

En referencia al contexto universitario, se producen una serie de aprendizajes complejos que permiten al estudiante, tanto la apropiación de los contenidos disciplinares, como la posibilidad de constituirse en sujeto en ese mismo aprendizaje.

Es por esto que la psicopedagogía encuentra en la universidad, un campo de intervención pertinente a partir del cual generar conocimientos y dispositivos ajustados a las necesidades contextuales y proponer la sistematización de marcos teóricos que abonen la constitución de dicho campo, integrando propuestas teóricas diversas en pos del diseño de estrategias que propendan al ingreso, permanencia y egreso universitario. Esto significa, vincular para complejizar, en base a propuestas como la teoría de la persistencia propuesta por Tinto (1989), el oficio de estudiante (Coulon, 1995), las Tutorías o Mentoría de pares (Mancovsky \& Lizzio, 2019), Aprendizaje colaborativo (Escribano \& Del Valle, 2018), Comunidades de aprendizaje (Tinto, 1993), Pedagogía universitaria (Lucarelli, 2009), la Psicología positiva (Barahona et al., 2013; Seligman, 1990), la Resiliencia (Lightsey, 2006).

Por último, un aspecto interesante que remite a la dimensión pedagógica es el lugar que adquiere la práctica, las ejemplificaciones y la generación de casos concretos como fuente de aprendizaje. Este aspecto señalado por los y las estudiantes, es consonante con la necesitad de pensar en prácticas docentes que van más allá de la clase magistral como método tradicional en la enseñanza universitaria. Una de las perspectivas posibles es la propuesta del Aprendizaje basado en problemas, el cuál tienen su base teórica en la psicología cognitiva, concretamente en el constructivismo. La premisa básica es que el aprendizaje es un proceso de construcción del nuevo conocimiento sobre la base del previo (Escribano \& Del Valle, 2018).

Lo que se pretende connotar es la necesidad de planificar didáctica y pedagógicamente contenidos que favorezcan la transposición didáctica y así la implicación de los estudiantes en su aprendizaje.

\section{REFERENCIAS BIBLIOGRÁFICAS}

Aguilera, E., \& Ortiz, E. (2009). Las investigaciones sobre los estilos de aprendizaje y sus modelos explicativos. Revista de estilos de aprendizaje, 2(4), 24-42.

Banks, M. (2010). Los datos visuales en investigación cualitativa (E. Morata (ed.)).

Barahona, N., Sánchez, A., \& Urchaga, J. (2013). La Psicología Positiva aplicada a la educación: 
el programa CIP para la mejora de las competencias vitales en la Educación Superior. Revista de Formación e Innovación Educativa Universitaria, 6(4), 244-256.

Bartolini, A., Vivas, D., Ferreira, C., \& Petric, N. (2015). Continuidades y discontinuidades de sentido entre relatos y metáforas. Dos entradas para la comprensión de los procesos de tesis. En Desafios profesionales y prácticas académicas en el campo de la investigación y la producción metodológica (pp. 69-80). Estudios Sociológicos.

Cabrera, L., Bethencourt, J., Alvarez, P., \& González, M. (2006). El problema del abandono de los estudios universitarios. Revista Electrónica de Investigación y Evaluación Educativa, 12(2), 171-203.

Camarero, F., Martín, F., \& Herrero, J. (2000). Estilos y estrategias de aprendizaje en estudiantes universitarios. Psicothema, 12(4), 615-622.

Cambours, A., \& Gorostiaga, J. (2016). Hacia una universidad inclusiva. Nuevos escenarios y miradas. Aique Grupo Editor.

Carli, S. (2012). El estudiante universitario. Hacia una historia presente de la educación pública. Siglo Veintiuno Editores.

Coulon, A. (1995). Etnometodología y educación. Paidós.

De la Barrera, M. (2007). Procesos de aprendizaje en alumnos universitarios. En D. Donolo \& C. Rinaudo (Eds.), Investigación en educación. Aportes para construir una comunidad más fecunda. La Colmena.

De la Fuente, J., Pichardo, M., Justicia, F., \& Berbén, A. (2008). Enfoques de aprendizaje, autorregulación y rendimiento en tres universidades europeas. Psicothema, 20(4), 705711. https://www.redalyc.org/pdf/727/72720430.pdf

Escribano, A., \& Del Valle, A. (2018). El aprendizaje basado en problemas. Una propuesta metodológica para la Educación Superior. Narcea Editores.

Heredia, N. (2018). Las experiencias en el aula. Una alternativa para aprender de la práctica docente. En Estrategias de enseñanza y aprendizaje para la docencia universitaria Experiencias desde el aula (pp. 7-21). Universidad de Colima.

Lightsey, O. (2006). Resilience, meaning and wellbeing. Counseling Psychologist, 34(1), 96-107.

Lucarelli, E. (2009). Teoría y práctica en la universidad. A la innovación en las aulas. Miño y Dávila Editores.

Mancovsky, V, \& Lizzio, G. (2019). Acompañamiento entre estudiantes pares: historias singulares sobre los inicios a la vida universitaria que interpelan la enseñanza. En Por una pedagogía de los inicios. Más allá del ingreso a la vida universitaria (pp. 113-126). Biblos.

Martin-Kniep, G. (2007). Portfolios del desempeño de maestros, profesores y directivos: la sabiduría de la práctica. Paidós.

Martínez, J. (2007). Concepción de aprendizaje y estrategias metacognitivas en estudiantes universitarios de psicología. Anales de Psicología, 23(1), 7-16.

Marton, F., \& Säljö, R. (1976). On qualitative differences in learning. I. The outcome and process. British Journal of Educational Psychology, 46, 4-11.

Morchio, I. (2015). Aprender a aprender como meta de la educación superior. Editorial Teseo.

Müller, M. (1999). Balance y perspectivas de la Psicopedagogía en la bisagra del milenio. Aprendizaje Hoy. Revista de actualidad psicopedagógica, XIX(44), 7-12.

Paivandi, S. (2019). La relación con el proceso de aprender en la universidad: un estudio sobre la perspectiva del aprendizaje de los estudiantes de la región parisina. En Viviana 
Mancovsky \& E. Más (Eds.), Por una pedagogía de «los inicios» Más allá del ingreso a la vida universitaria (pp. 44-68). Editorial Biblos.

Perrenoud, P. (2009). La construcción del éxito y del fracaso escolar. Morata.

Pozo, J., \& Puy, M. (2009). Psicología del aprendizaje universitario. La formación en competencias. Morata.

Salim, R. (2005). El cuestionario CEPEA: herramienta de evaluación de enfoques de aprendizaje en estudiantes universitarios. Revista Iberoamericana de Educación, 36(4), 1-9.

Seligman, M. (1990). Learned optimist. Pocket Books.

Soneira, A. (2006). La Teoría fundamentada en los datos (Grounded Theory) de Glaser y Strauss. En Estrategias de investigación cualitativa (pp. 153 - 173). Gedisa.

Strauss, A., \& Corbin, J. (2002). Bases de la investigación cualitativa. Técnicas y procedimientos para desarrollar la teoría fundamentada. Editorial Universidad de Antioquia.

Tinto, V. (1989). Definir la deserción: una cuestión de perspectivas. Revista de Educación Superior, XVIII(3), 1-9.

Tinto, V. (1993). Reflexiones sobre el abandono de los estudios superiores. Perfiles Educativos, $18(3), 35-52$.

Walker, V. (2012). El tránsito de los estudiantes por la universidad. Fundación Universitaria Andaluza Inca Garcilaso.

\section{Conflicto de intereses / Competing interests:}

Los autores declaran que no incurren en conflictos de intereses.

Rol de los autores / Authors Roles:

Natalia Petric: conceptualización, curación de datos, análisis formal, adquisición de fondos, investigación, metodología, administración del proyecto, recursos, software, supervisión, validación, visualización, escritura preparación del borrador original, escritura - revisar \& amp; edición.

Wilson Sicari: conceptualización, investigación, metodología, administración del proyecto, recursos, software, supervisión, validación, visualización, escritura - preparación del borrador original, escritura - revisar \& amp; edición.

Fuentes de financiamiento / Funding:

Los autores declaran que no recibieron un fondo específico para esta investigación.

\section{Aspectos éticos / legales; Ethics / legals:}

Los autores declaran no haber incurrido en aspectos antiéticos, ni haber omitido aspectos legales en la realización de la investigación. 